\title{
UNA APROXIMACIÓN A LA DISERTACIÓN “DE CASIBUS PERPLEXIS” DE G. W. LEIBNIZ COMO ESTRATEGIA DE SOLUCIÓN AL PROBLEMA CONTEMPORÁNEO DE LOS LLAMADOS “CASOS DIFÍCILES”*
}

[An Approach to G.W. Leibniz' "De Casibus Perplexis" Dissertation as the basis for a Strategy to solve the Contemporaneous Problem of the so-called "Difficult Cases"]

\author{
Johann BENFELD** \\ Pontificia Universidad Católica de Valparaíso, Chile
}

\begin{abstract}
RESUMEN
El trabajo expone la respuesta que frente al problema de los llamados "casos perplejos" dio G. W. Leibniz en su opúsculo De casibus perplexis. Se inicia con la exposición del debate entre Hart y Dworkin y el trasfondo teórico que está detrás de la discusión y avanza hacia la exposición del De casibus perplexis de Leibniz, como una tercera vía de solución a las aporías en el derecho. Una vez expuestas las teorías precisa las diferencias entre todas ellas, mostrando
\end{abstract}

\begin{abstract}
This work sets out the answer provided by G. W. Leibniz in his dissertation on $D e$ casibus perplexis to the so-called "perplexing cases" problem. It begins with Hart and Dworkin debate and the theoretical background behind the discussion, and then moves forward to Leibniz' De casibus perplexis, as a third way to solve aporias of law. Once the theories had been set out, the differences between them are pointed out, and their irreducibilities and the actual val-
\end{abstract}

ReCibido el 1 de junio y aCEPTADO el 30 de julio de 2015

* Un borrador de este trabajo ha sido previamente leído y discutido por los profesores Patricio Lazo y Enzo Solari. Muchas de sus observaciones y sugerencias han sido recogidas en esta versión final. A ellos pues mis agradecimientos. A don Alejandro Guzmán Brito, además de las conversaciones que hemos tenido sobre este tema, le debo una adecuada orientación sobre la bibliografía pertinente para escribir este artículo. Vaya a él también mi más sincero agradecimiento.

** Profesor de teoría y filosofía del derecho de la Pontificia Universidad Católica de Valparaíso. Doctor en derecho por la Universidad de Salamanca, España. Dirección postal: Facultad de Derecho, Pontificia Universidad Católica de Valparaíso, Avda. Brasil 2950, Valparaíso, Chile. Correo electrónico: johann.benfeldcv.cl 
su irreductibilidad y el valor actual que se le puede asignar a la propuesta de Leibniz.

\section{Palabras Clave}

Casos difíciles - Casos perplejos $-\mathrm{H}$. L. A. Hart - R. Dworkin - G. W. Leibniz. ue that can be ascribed to Leibniz proposal are determined.

\section{KEYWORDS}

Difficult cases - Perplexing cases $-\mathrm{H}$. L. A. Hart - R. Dworkin - G. W. Leibniz.

\section{Planteamiento de la cuestión}

Muchas son las razones por las cuales un caso judicial puede ser de difícil resolución, sin embargo, hay por lo menos dos causas genéricas que indiscutiblemente se cuentan entre ellas: la falta de previsión legal del supuesto de facto constitutivo de la pretensión y la ambigüedad propia del lenguaje de las normas jurídicas. Así, siempre que un juez se enfrenta a un caso respecto del cual no dispone de norma expresa que lo dirima o existiendo alguna no hay claridad sobre su verdadero sentido y alcance, dicho caso aparecerá ante sus ojos como lo que técnicamente se denomina un "caso difícil" 1.

Los "casos difíciles", aunque constituyen una anomalía dentro de la actividad jurisdiccional, han sido históricamente estudiados por su importancia práctica y teórica. Desde un punto de vista práctico, constituyen tanto un problema como un desafío para la actividad jurisdiccional, pues ponen en evidencia la precariedad de todo sistema normativo. En efecto, no existe ordenamiento jurídico alguno que pueda prever todos los supuestos fácticos de activación de las normas, ni suprimir la ambigüedad propia con la que muchas de sus disposiciones expresan su contenido prescriptivo. Desde un punto de vista teórico, estos llamados "casos difíciles", a su vez, han sido vistos por los operadores jurídicos como una oportunidad para mostrar las fortalezas y debilidades de las teorías iusfilosóficas en torno a la naturaleza de lo jurídico.

Por lo anterior, los "casos difíciles" son considerados verdaderos vasos comunicantes entre la práctica y la teoría; en cuanto permiten que a propósito de una actividad particular y concreta (la acción de juzgar) se expresen las razones

${ }^{1}$ Término complejo con el cual se alude, contemporáneamente, a una situación generalmente de facto que opera como antecedente de una proposición hipotética ("si, entonces [...]”), de la cual, previa interpretación y subsunción, se siguen consecuencias normativas de naturaleza jurídica. El adjetivo “difícil” en este contexto expresa la idea de falta de previsión del caso en el sistema legal. Desde esta perspectiva, por ejemplo, no resulta difícil imaginar un caso anómalo para el sistema legal. En tal sentido, Foucault, Michele, Los anormales (Buenos Aires, Fondo de Cultura Económica, 2010), p. 71 nota, cita un caso bastante curioso: se trataba de "la historia de dos hermanos siameses, uno de los cuales había cometido un crimen, y el problema consistía en saber si había que ejecutar a uno o a los dos. Si se ejecutaba a uno, el otro moriría, pero si se dejaba vivir al inocente, también había que dejar vivo al otro". La solución, según lo refiere el propio Foucault citando a SAUVAL, H., Historie et recherches des antiquités de la ville de Paris (Paris, 1724), II, p. 564, fue la siguiente: "Como llegó a matar a un hombre de una cuchillada (uno de los siameses), se lo procesó y fue condenado a muerte; pero no se lo ejecutó, a causa de su hermano, que no tenía parte alguna en ese asesinato, y no podía hacerse morir a uno sin hacer morir al otro al mismo tiempo". 
del derecho (consideraciones ius filosóficas que legitiman la acción de juzgar aún en ausencia de regla positiva). En tal sentido, no es de extrañar que una de las discusiones teóricas más interesantes del siglo XX haya sido precisamente sobre la naturaleza de estos casos. Específicamente, nos referimos al llamado "debate Hart-Dworkin".

El "debate Hart-Dworkin", del cual más adelante hablaremos, se inscribe en un registro contemporáneo muy preciso sobre el tema: partiendo de la idea de la existencia inevitable de los "casos difíciles", por indeterminaciones de facto o imprecisiones del lenguaje jurídico, avanza en la especificación de los criterios (incluso extra jurídicos) que ha de usar el juez (y sólo éste) para la resolución del asunto, mostrando qué tipo de razones son admisibles para la resolución de estos casos.

La discusión sobre los "casos difíciles", sin embargo, no se inicia con el debate Hart-Dworkin y, por ello, no siempre ha tenido un mismo horizonte de discusión. Una idea muy diferente sobre el particular la encontramos, por ejemplo, en el De casibus perplexis de Leibniz, obra en la cual, adelantando un poco sus ideas, se discute la necesidad lógica y ontológica de los llamados "casos difíciles"; se afirma que frente a los "casos difíciles" sólo caben razones jurídicas, e incluso se responde de una diversa manera a la pregunta sobre el verdadero rol del juez en estos casos. Por esta razón, en lo que sigue intentaremos mostrar en qué medida la propuesta de Leibniz, respecto a los llamados “casos difíciles", representa una solución diferente a las estrategias contemporáneas sobre la materia. Para lograr nuestro cometido, en primer lugar, expondremos de manera general el debate Hart-Dworkin y el trasfondo teórico que, creemos, está detrás de la discusión (II). Luego, en un segundo momento, examinaremos la respuesta que frente al problema de los llamados "casos perplejos" dio G.W. Leibniz en su De casibus perplexis (III). Finalmente, a modo de conclusión, veremos las diferencias irreductibles entre las estrategias contemporáneas (representadas en el "casos difíciles" (IV).

\section{UNA DISCUSIÓN CONTEMPORÁNEA: EL DEBATE ENTRE}

\section{H. L. A. Hart y R. DwOrKIN}

Aun cuando no se trata de un tema completamente nuevo para la filosofía y la teoría del derecho, los últimos años han sido muy productivos en orden a delimitar conceptualmente la noción de "caso difícil”. Este renovado interés de la filosofía jurídica por los problemas asociados a los llamados casos complejos o difíciles se debe, en parte, a los trabajos de Ronald Dworkin, quien en 1967 publicó un pequeño artículo titulado The Model of Rules con el que pretendía poner de manifiesto las deficiencias de la teoría iuspositivista de H. L. A. Hart.

En el The Model of Rules Dworkin escribe: "quisiera realizar un ataque general al positivismo, y usaré la versión de H. L. A. Hart como objetivo, toda vez que se requiere un objetivo particular. Mi estrategia será organizada sobre el hecho que cuando los abogados disputan sobre derechos y obligaciones, particularmente en aquellos "casos difíciles" cuando nuestros problemas con esos conceptos parecen más acuciantes, ellos hacen uso de criterios que no funcionan como reglas, sino que operan de manera diferente como principios, políticas y otras clases de crite- 
rios" ${ }^{2}$. Años después, Dworkin volvería con mayor precisión y profundidad sobre estas ideas en otro trabajo titulado ahora simplemente Hard Cases aparecido en la Harvard Law Review en abril de 1975.

Muy pronto las ideas de Dworkin recibieron su réplica desde la órbita del ius positivismo, primero de una forma un tanto desarticulada y tímida por parte de algunos promotores de la filosofía de Hart, y más tarde de manera más clara y contundente del propio H. L. A. Hart. De ahí en adelante la cuestión de los "casos difíciles" quedó indisolublemente ligada al llamado "debate Hart-Dworkin"3. Este debate, en gran parte, tiene su centro de gravedad en la discusión sobre la viabilidad del proyecto iuspositivista de Hart y sus consecuencias para la actividad jurisdiccional. En el contexto de esta discusión la cuestión a resolver es cómo han de solucionarse los "casos difíciles" para el derecho, puesto que ellos (aunque no exclusivamente) tienen la aptitud de poner de manifiesto ciertas dificultades de interpretación y aplicación del mismo.

1. Hart y la idea de la textura abierta del lenguaje y la discrecionalidad judicial.

Para Hart, los "casos difíciles" se presentan debido a la "textura abierta del lenguaje”, es decir, "cualquiera que sea la técnica, precedente o legislación, que se escoja para comunicar pautas o criterios de conducta, y por mucho que éstos operen sin dificultades respecto de la gran masa de casos ordinarios, en algún punto en que su aplicación se cuestione las pautas resultarán ser indeterminadas; tendrán

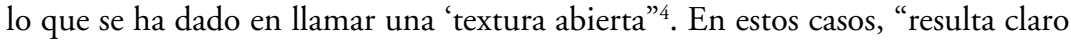
que la autoridad que elabora la regla tiene que actuar en forma discrecional, y que no cabe la posibilidad de tratar el problema que crean los casos diversos como si hubiera una única respuesta correcta, es decir, una solución que no sea un mero compromiso razonable entre muchos intereses en conflicto" 5 .

Estos "casos difíciles" que ponen de manifiesto la textura abierta del lenguaje normativo cumplen, además, una importante función dentro del ordenamiento jurídico, pues permiten la realización de los propósitos del derecho evitando los vicios del conceptualismo y formalismo jurídico. Conforme a éstos últimos hay que aferrarse a "ciertas características presentes en el caso obvio, e insistir en que ellas son a la vez necesarias y suficientes para que todo aquello que las posea quede comprendido por la regla, cualesquiera que sean las restantes características que

${ }^{2}$ Dworkin, Ronald M., The Model of Rules (1967), Faculty Scholarship Series, Paper 3609, p. 22.

${ }^{3}$ En la literatura anglo se suele designar esta discusión como "Hart-Dworking Debate"; aunque lo cierto es que H. L. A. Hart tardó muchos años en contestar de manera general y sistemática a las objeciones de Dworkin (cuestión que hizo en el "Post scriptum" a su libro El concepto de derecho de 1994). En tal sentido no se trató de una verdadera discusión entre dos autores, sino más bien de las objeciones formuladas por Dworkin a Hart y las respuestas que recibió el primero de parte de pensadores iuspositivistas cercanos a Hart; por lo menos hasta la aparición del "Post scriptum". Véase, a este respecto, HarT, H. L. A., "Post Scritum" a su libro El concepto de derecho (Ciudad de México, Universidad Nacional Autónoma de México, 2000), pp. 9 ss.

${ }^{4}$ Hart, H. L. A., El concepto de derecho (Buenos Aires, Abeledo-Perrot, 1998), p. 159.

${ }^{5}$ Ibíd., p. 164. 
pueda tener, y cualquiera que sean las consecuencias sociales que resulten de aplicar la regla de esta manera" ${ }^{6}$. Sin embargo, este modo de proceder implica tener que incluir en el ámbito de aplicación de la regla ciertos casos que normalmente y por diversas consideraciones desearíamos excluir, lo que en los hechos llevará a que "la rigidez de nuestras clasificaciones entrará así en conflicto con los propósitos que nos animan al tener o preservar la regla"

Por cierto, la idea de que los casos difíciles demandan de parte de los tribunales un margen no menor de discrecionalidad no supone desconocer la existencia y el valor de las reglas como preceptos generales, sino simplemente renunciar a la posibilidad de responder de manera mecánica, a priori y de una sola forma a todos los problemas que surgen en el tráfico jurídico. Ello es así por la sencilla razón de que siempre habrá una relativa ignorancia respecto de los hechos y los propósitos comprendidos en la regulación. "Si el mundo en el que vivimos estuviera caracterizado únicamente por un número finito de notas y éstas, junto con todos los modos que pudieran combinarse, fueran conocidas por nosotros, podríamos formular provisiones por adelantado para toda posibilidad. Podríamos elaborar reglas para cuya aplicación a todos los casos particulares nunca exigiera una nueva elección. Todo podría ser conocido y, por ello mismo, las reglas podrían especificar por adelantado la solución para todos los problemas. Este sería un mundo adecuado para la teoría jurídica 'mecánica"”.

\section{Dworkin: Hércules y la única solución adecuada.}

Dworkin, a su vez, comparte con Hart la idea de que los "casos difíciles" ponen de manifiesto la falibilidad de los sistemas de reglas; sin embargo, no está dispuesto a admitir que el derecho se agote en un sistema de reglas que, por su propia naturaleza (textura abierta del lenguaje regulativo) suponga siempre un acto discrecional del órgano jurisdiccional a fin de resolver los casos legales anómalos (ideas que él piensa sostiene Hart). En tal dirección en su Hard Cases de 1975 retoma el discurso que había iniciado en The Model of Rules de 1967 y en Social Rules and Legal Theory de $1972^{9}$; pero ahora centrando su atención en la noción de "caso difícil".

Para Dworkin, en general, hay dos clases de "casos difíciles": i) aquéllos para los cuales no existe una ley o precedente judicial que los resuelva; y ii) aquéllos que no pueden ser resueltos a la luz de una interpretación, reinterpretación o extensión de la ley o el precedente existente en el sistema ${ }^{10}$. En ambos casos, los jueces no han de resolver de forma discrecional, sino conforme a principios que se encuentran presentes en el propio sistema político. Estos principios, que Dworkin conceptualmente distingue de las políticas generales, se extraen del ordenamiento jurídico y en tal sentido no derivan de intereses particulares o colectivos del cuerpo social, ni suponen la creación de nuevos deberes jurídicos;

\footnotetext{
${ }^{6}$ Ibíd., pp. 161-162.

${ }^{7}$ Ibíd., p.162.

${ }^{8}$ Ibíd., p. 160 .

${ }^{9}$ Véase Dworkin, Ronald, Social Rules and Legal Theory, en Yale Law Journal, 8 (1972).

${ }^{10}$ Véase Dworkin, Ronald, Hard Cases, en Harvard Law Review, 88 (1975), p. 1058.
} 
sino simplemente la toma de conciencia y la explicitación de los derechos que ya están contenidos en el sistema ${ }^{11}$.

Los principios, en el contexto de Hard Cases, son proposiciones que expresan un derecho individual; que describen derechos ${ }^{12}$. Y en su implementación, los jueces han de observar lo que Dworking llama "el principio de responsabilidad política”. Conforme a este principio, cuando se resuelve un caso (difícil o no) los tribunales de justicia han de fallar de manera general y consistente ${ }^{13}$, pues en el fondo la actividad jurisdiccional supone una teoría política comprehensiva que habilita al juez tanto para resolver el caso sometido a su conocimiento como para justificar argumentativamente que la solución por él propuesta se deriva inequívocamente del propio "background" político del sistema. En este sentido, la actividad jurisdiccional, incluso a propósito de los "casos difíciles", no se reduce nunca al mero ejercicio de una potestad discrecional ${ }^{14}$.

Para caracterizar su interpretación sobre la forma en que han de resolverse los “casos difíciles”, Dworkin introduce la figura del juez Hércules, algo así como "un abogado con súper habilidades, conocimientos, paciencia y perspicacia" 15 . Y, a propósito de la manera en que éste ha de proceder frente a los "casos difíciles" escribe: "Él debe construir, por así decir, una teoría constitucional; dado que él es Hércules nosotros podemos suponer que él puede desarrollar una teoría política completa que justifique la constitución como un todo. Debe ser un esquema que ajuste las reglas particulares de esa constitución, por supuesto" ${ }^{16}$.

Esta especial manera de concebir la actividad de los tribunales de justicia busca poner de manifiesto, en el fondo, qué ha de ser considerado derecho en un sistema jurídico en curso. Ya no se trata simplemente de la aplicación reiterada en el tiempo de una ley o un precedente, sino más bien de entender que "la fuerza gravitacional del precedente (o de la ley) puede ser explicada mediante la apelación, no a la sabiduría de hacer cumplir el precedente, sino a la equidad de tratar de manera similar a los casos" ${ }^{17}$; de manera tal que "Hércules, cuando define la fuerza gravitacional de un precedente particular, debe tener en consideración sólo el argumento de principio que justifica ese precedente" ${ }^{18}$. Con esto Dworkin termina de definir su teoría ya no sólo como una concepción política comprehensiva de la actividad jurisdiccional, sino como una verdadera teoría moral de la política y el derecho que, por lo menos conjeturalmente y de la mano de Hércules, está en condiciones de resolver todo caso difícil de una manera cierta, segura y justa. Pues, por lo menos en teoría, todo caso difícil tiene sólo una respuesta correcta que, por cierto, nada tiene que ver con la discrecionalidad de los jueces ${ }^{19}$.

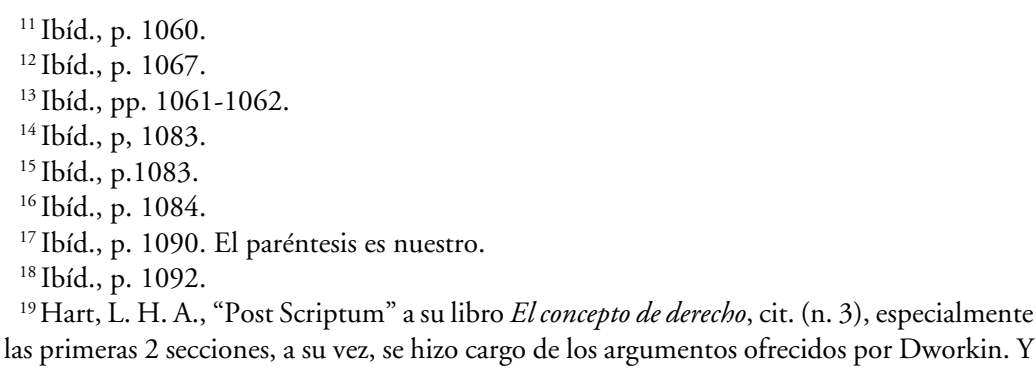




\section{El trasfondo del debate Hart-Dworking: una cuestión moral.}

El "debate Hart-Dworkin" duró décadas e incluso al día de hoy no hay un verdadero acuerdo sobre cuál de las posiciones finalmente logró imponer sus ideas. Sin embargo, la discusión sirvió para poner de manifiesto la importancia de los "casos difíciles" para la teoría y filosofía del derecho. En tal sentido, Hart y Dworkin afirman que los casos difíciles son inevitables en el derecho, tanto por la textura abierta del lenguaje como por la imposibilidad de la regla de derecho de prever todos los casos posibles de su aplicación; su existencia, además, no debe ser considerada como un elemento negativo, sino todo lo contrario ${ }^{20}$. Los casos difíciles permiten la realización de los propósitos del derecho y, en tal dirección, las soluciones que desde ellos se promueven operan ya como criterios de interpretación de la regla jurídica positiva, ya como principios rectores de la creación de nuevas reglas de derecho. Ambos autores difieren, con todo, en la estrategia y criterios para la resolución de estos casos. Para Dworkin los casos difíciles demandan la aplicación de principios descubiertos en una práctica argumentativa no discrecional que extrae sus ideas del extrarradio jurídico, esto es, de la teoría política y de la moral. Puntos que, por cierto, no comparte Hart.

Tal vez sea este último aspecto del debate (la posibilidad de introducir en el discurso jurídico elementos extra jurídicos bajo la forma de principios) el que explica la irreductibilidad de una y otra posición; pues como ha señalado Shapiro, a pesar de las complicaciones para entender la discusión, "hay una importante unidad en el debate Hart-Dworkin que puede ser descrita en una forma relativamente simple. Propondré en lo que sigue, que el debate está organizado en torno a uno de los asuntos más profundos de la filosofía del derecho, a saber, la relación entre legalidad y moralidad. La estrategia básica de Dworkin a través del

éste, por su parte, desarrolló con mayor claridad y matices diversos sus críticas a Hart en sus obras posteriores: Taking Right Seriously de 1978; Law's Empire de 1986 y Justice in Robes de 2006. Es cierto que Dworkin fue variando sus argumentos en el tiempo y que de una mera crítica al positivismo de reglas contenido en sus primeros trabajos llegó, finalmente, a la elaboración de una teoría interpretativa del derecho desde la cual puede ser criticado cualquier forma de positivismo jurídico. Sin embargo, a los propósitos de este artículo baste con lo dicho hasta el momento.

${ }^{20}$ Por cierto, desde el punto de vista de la técnica legislativa no todos los autores del dominio anglosajón están de acuerdo en que los casos difíciles permiten aclarar lo que el derecho es. En tal dirección constituyen un lugar común las palabras de HOLMEs, Oliver Wendell, fallo de disenso en "Securities Co. v. United States", 193, U.S., 197,400-1 (1904), para quien: "los grandes casos como los "casos difíciles" hacen mal derecho. Pues los grandes casos son llamados grandes no por su real importancia en dar forma al derecho del futuro, sino por causa de algún abrumador interés inmediato que apela a los sentimientos y distorsiona el juicio. Esos intereses inmediatos ejercen una clase de presión hidráulica que permite que lo que era previamente claro parezca dudoso, y ante los cuales se torcerán incluso principios bien asentados de derecho" Véase, también para la discusión de la máxima "Hard cases make bad law": Rostow, Eugene, Great Cases Make Bad Law: The War Powers Act, en Texas Law Review, 50 (mayo de 1972) 5; SHAUER, Fedrick, Do Cases Make Bad law? en The University of Chicago Law Review, 73 (2006) 3; White Speight, Hallie, Hard Cases make Bad Law: "Commonwealth v. Adjutant" and Evidence of the Deceased's Propensity for Violence in Self-Defense Cases in Massachussets, en Boston University Law Review 86 (2006) 3. Todos estos textos, en general, ponen en duda las bondades de extraer principios generales de "casos difíciles" particulares cuya ocurrencia es más bien anómala. 
curso del debate ha sido argumentar que, de una forma u otra, la legalidad está determinada últimamente no sólo por hechos sociales, sino también por hechos morales. En otras palabras, la existencia y contenido del derecho positivo está, en el análisis final, gobernada por la existencia y contenido moral del derecho. Esta afirmación, por tanto, directamente desafía e intenta destruir la imagen positivista sobre la naturaleza del derecho, para la cual la legalidad nunca está determinada por la moralidad sino, más bien, por la práctica social. Pues si los jueces deben considerar lo que la moralidad demanda en orden a decidir qué requiere el derecho, los hechos sociales solos no pueden determinar el contenido del derecho. Como era de esperar, la respuesta de Hart y sus seguidores ha sido argumentar que dicha dependencia de la legalidad respecto de la moralidad o es meramente aparente o no tiene la aptitud, en los hechos, para socavar los fundamentos sociales del derecho y el sistema legal"21.

Si la interpretación precedente es correcta, la cuestión de los casos difíciles, por lo menos en el debate Hart-Dworkin, se refiere a la determinación de la existencia y contenido del derecho positivo a propósito de un caso, esto es, un conflicto particular que ha de ser resuelto a la luz de una regla o principio general mediante una interpretación y adjudicación judicial. Así las cosas, habrá tantos casos difíciles cuantos intereses no previstos en el ordenamiento jurídico (por omisión, imposibilidad de extensión o comprensión) las partes pretendan elevar a la categoría de derechos ante el juez.

\section{Dos ejemplos ilustrativos de la discusión.}

Veamos a continuación dos de estos llamados “casos difíciles” para ilustrar lo que venimos diciendo. El primero, llamado "Rex vs. Taylor" lo encontramos en El Concepto de Derecho de H.L.A. Hart, específicamente al final del capítulo 7o; el segundo caso, llamado "Elmer", lo hallamos al comienzo del Imperio de la Justicia de Dworkin.

a) "Rex vs. Taylor". El señor Rex parecía tener un impulso irresistible a contraer matrimonio. La primera vez que lo hizo fue en 1925 con Alice Julie Taylor. Sin embargo, un único matrimonio muy pronto le pareció poco y en 1927 contrajo, sin desvincularse de la señora Taylor, nuevamente nupcias con otra. Y luego, a pesar de sus dos mujeres anteriores, en 1942 con una tercera. En 1944 fue demandado por el delito de bigamia, por su "tercera" mujer, pero se libró de la condena al demostrar que su segundo matrimonio no era tal, al existir un vínculo anterior no disuelto.

En 1945 las cosas se complicaron para el señor Rex, pues fue acusado, ahora sí correctamente, de bígamo por tener un vínculo válido con Alice Taylor. Nuevamente, apelando a algunas estrategias legales se libró de la acusación, al demostrar que habían pasado más de siete años sin tener noticias de la señora Taylor antes de contraer un nuevo vínculo. Eso sí, esta vez fue acusado de falso testimonio ante el oficial de la administración.

${ }^{21}$ Shapiro, Scott, The "Hart-Dworkin Debate": A Short Guide for the Perplexed, en Public Law and Legal Theory. Working Paper Series, Working Paper No. 77 (marzo de 2007), p. 5 [disponible en: http://ssrn.com/abstract=968657]. 
El señor Rex, con todo, no dejó transcurrir siquiera un año antes de contraer nuevamente matrimonio, ahora con Lilian Smithers para luego dejarla y volver a casarse, por cuarta vez, con Olive Briggs en 1948. Ese mismo año, nuevamente es demandado por el delito de bigamia y ahora es finalmente condenado a una pena privativa de libertad. En realidad, en este nuevo juicio y por consejo de su propio abogado ni siquiera se defendió, sino que se limitó a aceptar los cargos.

Básicamente dos fueron las razones que motivaron al señor Rex a no defenderse. En primer lugar, estaba el Estatuto 1, James 1, c. 11, que disponía que cualquier persona que contrajera nuevas nupcias sin estar disuelto el vínculo anterior, ya fuera una o varias veces, dentro del territorio de su majestad, cometería el delito de bigamia. En un proviso, eso sí, aclaraba que la normativa no se aplicaba si el acusado en cuestión probaba que por espacio de siete años continuos no hubiera tenido noticia alguna de su cónyuge.

Interpretando dicho estatuto, la Corte en el caso "R. vs. Treanor (o McAvoy)" había sostenido en 1939 que el cómputo de los siete años se aplica sólo para el primero de los matrimonios posteriores respecto del cual se demandaba el delito de bigamia. En este contexto, el abogado del señor Rex le había advertido que su caso estaba condenado al fracaso.

Sin embargo, en 1950 el señor Rex interpuso un recurso de apelación en contra de la sentencia condenatoria del juicio de 1948. Los argumentos de la apelación avanzaron en dos direcciones. Primera, la interpretación anterior del estatuto en cuestión por parte de la Corte fácilmente podría llevar a resultados contra intuitivos. Así, por ejemplo, no podría ser condenado uno que siete años después de las últimas noticias de su legítima mujer contrajese nuevo vínculo. Pero si el mismo sujeto, una vez muerta su segunda mujer volviese a contraer matrimonio, aunque fuera diez años más tarde, sí podría ser condenado por bígamo; pues los siete años sólo cuentan para el primero de los matrimonios posteriores. El segundo argumento de la defensa del señor Rex se basó en la idea de que la Corte sí podía desconocer o apartarse de un precedente cuando éste fuera manifiestamente injusto.

Finalmente la Corte de Apelaciones acogió en sede civil la pretensión del señor Rex y, aduciendo razones de buen criterio y justicia, aceptó a tramitación el recurso para luego acogerlo y dejar en libertad al condenado (no sabemos, en todo caso, si el señor Rex escarmentó o no con eso de los matrimonios). Hart intenta mostrar con este caso que todo estatuto requiere siempre de interpretación debido a la textura abierta del lenguaje jurídico (¿el estatuto se refería sólo a la bigamia o también a la poligamia?; ¿desde cuándo se computan los siete años?; ¿se suma el tiempo entre matrimonios diversos?, etc.). Además, el caso sirve para ilustrar su tesis de la discrecionalidad judicial como creadora de derecho; pues luego del fallo "Rex vs. Taylor" está claro que el derecho es, en última instancia, lo que los jueces dicen conforme a un sistema de reglas, incluso cuando lo que dicen está en desacuerdo con sus dictámenes anteriores. Y si las reglas de derecho nada dicen con mayor razón su silencio ha de ser llenado por la actividad jurisdiccional de forma discrecional aunque no arbitraria ${ }^{22}$.

\footnotetext{
${ }^{22}$ Véase HarT, H. L. A., El concepto, cit. (n. 4), pp. 183-191.
} 
b) "Elmer". En 1882 en el Estado de Nueva York, el ciudadano conocido como "Elmer" dio muerte a su abuelo. Su intención era asegurar para sí la cuantiosa herencia que su abuelo había dispuesto en su favor unos años antes; pero que ahora peligraba. En esos años el testamento estaba regulado por diferentes estatutos especiales que se limitaban a señalar la forma y requisitos de validez de la realización del acto. En ninguno de dichos estatutos, por cierto, figuraba la idea de "no matar al causante" como un requisito de validez del acto.

La cuestión era entonces determinar jurídicamente si Elmer era el legítimo heredero universal de la fortuna de su abuelo (dejando fuera a la nueva cónyuge del causante y a sus dos hijas legítimas) o si, por el contrario, se le podía privar de la herencia.

Uno de los miembros del tribunal (el juez Gray) fue del parecer de diferir la herencia a Elmer. Basado en una interpretación literal, Gray mostraba que es imposible decidir a posteriori cuál habría sido la intención del causante de haber sabido que sería asesinado por su nieto; tal vez incluso en este caso habría decidido dejarle la herencia. Además, si a Elmer se le privase de la herencia se le estaría castigando dos veces, ya con una pena aflictiva, ya con una pena patrimonial, etc. Los otros miembros del tribunal, empero, fueron de otra opinión. El voto de mayoría lo escribió el juez Earl y su razonamiento avanza en la dirección de distinguir en todo estatuto entre un contenido literal y uno intencional. En este último, Earl advierte que no es posible pensar que los redactores del estatuto quisieran que un asesino heredara, pero que como parecía algo evidente no fue necesario incorporarlo al texto.

Esta idea, en todo caso, no supone que la teoría en juego sea la de la intención del legislador. Resulta claro que aquél no está en condiciones de prever "todos" los casos convenientes o de "clausurar" todas las situaciones prohibidas. En otros términos, hay cosas no previstas en un estatuto que se entienden forman parte de las intenciones de sus promotores (ciertos bienes que al momento de la realización de un estatuto testamentario no existían y ahora sí, claramente se puede entender que forman parte de lo que se puede heredar), y cosas no previstas que es discutible que hayan sido o no deseadas por los redactores de un estatuto. Más bien la idea de Earl parece aproximarse a la propuesta de falsación de Popper, pero en clave jurídica. Así, la cuestión no es tanto qué intención tenía el legislador o redactor del estatuto, sino más bien qué cosas, teniendo en consideración su entorno sociocultural ningún legislador hipotético habría estado dispuesto a aceptar como disposición testamentaria. Desde este punto de vista, los jueces en el caso Elmer, fallaron en su contra y lo privaron de la herencia, aunque los estatutos especiales no contemplaban el supuesto de asesinar al causante.

El caso Elmer sirve para ilustrar las ideas de Dworkin. En una situación tal (ahora debido a la falta de norma expresa) el juez ha de mirar a su contexto "cultural" y, a partir de aquél, responder la pregunta sobre qué tipo de conducta le parece, desde todo punto de vista y teniendo todos los elementos de juicio a su disposición, inaceptable para un legislador hipotético y omnicomprensivo ${ }^{23}$.

${ }^{23}$ Véase Dworkin, Ronald, El imperio de la justicia (Barcelona, Gedisa, 2005), pp. 24-28. 
Así pues, en casos semejantes, y siguiendo las ideas del debate Hart-Dworkin la cuestión se resuelve, o bien, de acuerdo al criterio discrecional del juez mediante la aplicación de ciertas reglas de derecho positivo presentes en el sistema, o bien, de acuerdo a principios del acervo político cultural presente en el "background" del sistema jurídico que el juez hubiese descubierto argumentativamente.

Aunque Hart y Dworkin ofrecen respecto del problema de los "casos difíciles" alternativas no conmensurables entre sí, ambos parecen estar de acuerdo en que para la solución de los "casos difíciles" el juez siempre habrá de recurrir a elementos extra jurídicos para encontrar la solución adecuada. En Hart dicha solución proviene del buen criterio del juez como órgano nomotético; en Dworkin la respuesta a estos "casos difíciles" se halla presente en el sistema político constitucional en el cual el juez opera. Así las cosas, pareciera ser que los jueces, para la resolución de estos casos, o bien, han de recurrir a su buen criterio y a la norma jurídica positiva, o bien, a la moral y a la política como criterio interpretativo de lo jurídico en el contexto de una sociedad democrática y constitucional en curso, no existiendo otro camino.

Sin embargo, otra estrategia de solución para los "casos difíciles" sí existe, pero para acceder a ella hay que abandonar la órbita de la discusión contemporánea sobre el particular y retroceder hasta el siglo XVII. En este contexto aparece la figura de G.W. Leibniz, quien a muy temprana edad enfrentó la misma dificultad a la que las teorías de Hart y Dworkin pretenden dar respuesta, pero desde un horizonte racionalita de diverso cuño y alcance.

\section{LEIBNIZ Y SU "DE CASIBUS PERPLEXIS"}

De casibus perplexis es el título de una dissertatio que G. W. Leibniz presentó en 1666 en la Universidad de Altdorf para la colación del grado de doctor en derecho, luego de que su candidatura fuera rechazada en la Universidad de Leipzig por motivos no del todo claros. El objeto de esta pequeña obra es la determinación conceptual de la noción de "caso complejo" en el derecho, específicamente en la etapa de aplicación del mismo, y de los criterios racionales para la resolución de los dichos casos de una forma necesaria, predecible y universalizable.

\section{El contexto del "De casibus perplexis".}

Cuando Leibniz escribió el De casibus perplexis faltaba poco más de un siglo para que Europa continental viera nacer los primeros códigos legales de inspiración racionalista; por tanto, este escrito temprano (Leibniz tenía tan sólo 20 años de edad) no trata de la codificación ni de los problemas asociados a ella (unidad, coherencia y plenitud del ordenamiento), sino de las cuestiones vinculadas a la interpretación y aplicación del derecho común en el contexto alemán de la época. Y aunque el problema precedente no era novedoso en el momento en que Leibniz escribe el De casibus, la perspectiva que adopta para su resolución sí lo es. Con todo, para entender el nuevo enfoque con el que Leibniz aborda el problema de los casos complejos en el derecho es necesario contextualizar su pensamiento, es decir, es menester precisar el registro intelectual en el que se inserta la reflexión sobre lo jurídico. 
Leibniz creció en un ambiente favorable para el estudio de las ciencias y el derecho. Los siglos XVI y XVII fueron muy importantes en Europa para el desarrollo de las ciencias. Especialmente la matemática y la física vieron en el transcurso de unos pocos años ampliados sus horizontes como nunca antes ${ }^{24}$. Tal vez por eso, Leibniz, desde muy joven haya mostrado un interés particular por los problemas matemáticos y, sobre todo, por la aplicación del método lógico deductivo a otras esferas del conocimiento. De hecho, el mismo año que aparece su De casibus perplexis, publica De arte combinatoria con el que pretendía obtener una plaza en la facultad de Filosofía de la Universidad de Leipzig y que avanza precisamente en la dirección antes indicada.

Además de las influencias de época, Leibniz heredó de su entorno próximo una fuerte vocación jurídica. En su hogar disponía de una copiosa biblioteca herencia de su abuelo materno, el famoso jurista Wilhelm Schumck. Igualmente, las visitas regulares al hogar paterno de su tío Johann Strauch (quien según palabras del propio Leibniz, influyera de manera determinante en su vocación de jurista) y de Quirinius Schacher (quien, debido a la temprana muerte de Schumck, fuera el tutor de la madre de Leibniz hasta que ésta contrajo matrimonio), ambos juristas, de primer nivel, propiciaban al joven Leibniz un entorno favorable para desarrollar una carrera como jurista. Por ello no extraña que muy pronto Leibniz haya iniciado, de manera simultánea a sus estudios de filosofía, estudios regulares de derecho en la Universidad de Leipzig.

Sin embargo, rápidamente Leibniz comprendió, a su pesar, cuán lejos estaba el derecho de saciar su ansia de conocimiento científico. El panorama que a la sazón ofrecía el derecho alemán (y el resto de Europa en general) era desolador. No había suficiente claridad respecto al sistema de fuentes: el derecho común, el derecho regio, el derecho canónico, los estatutos municipales, etc., se disputaban la primacía los unos respecto de los otros. Y en la confusión, las sentencias judiciales paso a paso ganaban terreno, pero sobre un suelo nada seguro (la discrecionalidad de los jueces). Probablemente este escenario haya marcado los esfuerzos de Leibniz en orden a intentar una aproximación científica al derecho. Para la realización de esta empresa era menester unir lo que al momento se hallaba separado: la metodología y el lenguaje de las ciencias (lógico-matemático) con el derecho. En tal sentido, los esfuerzos intelectuales del joven Leibniz en 1666 pueden ser vistos como un intento por mostrar la unidad intrínseca de la ciencia. De forma tal que el De arte combinatoria y el De casibus perplexis se pueden leer como partes de un mismo relato: uno muestra el método y el otro la aplicación del mismo al estudio

${ }^{24}$ Sin embargo, no fueron las universidades alemanas las que mayormente avanzaron en estas materias. De hecho, comparado con el desarrollo que mostraban sus pares de Inglaterra y Francia no estaban en condiciones de exhibir grandes logros. Véase Jourdain, Philip, The Logical Work of Leibniz, en The Monist, 26 (octubre de 1916) 4, p. 510 . Algunos años más tarde, cuando Leibniz traba relación con algunos de los matemáticos franceses, ingleses y holandeses más importantes de su época, su interés por las matemáticas y por la posibilidad de aplicar los métodos propios de esta ciencia a otras áreas del saber humano se ve confirmado y potenciado. En esta época serán para él de especial interés los trabajos de Christiaan Huygens, John Pell y Gabriel Mouton, entre otros. 
de lo jurídico. Por lo anterior, antes de revisar el opúsculo jurídico de Leibniz es menester que nos detengamos, aunque sea incidentalmente, en algunas de las ideas presentes en el De arte combinatoria.

\section{El proyecto lógico-matemático y jurídico de Leibniz: la ciencia como unidad} del saber.

En el De arte combinatoria es posible advertir el proyecto intelectual vital de Leibniz. La idea básica de este pequeño texto, simplificando mucho las cosas, es desarrollar una suerte de cálculo aritmético que admite poner en relación conceptos simples y complejos a través de la formulación de unos cuantos teoremas que permiten la clasificación de los conceptos y su adscripción a diferentes campos del saber humano. Así las cosas, el arte de la combinación permite afirmar, según Leibniz, que "las demostraciones perfectas son posibles en todas las disciplinas" 25 , y el derecho, por cierto, no escapa a esta realidad. Leibniz incluso va más lejos, y afirma que los puntos de contacto de la matemática y el derecho son mucho más profundos de lo que generalmente se piensa. "La jurisprudencia es similar a la geometría en otras cosas, es también similar en que ambas tienen elementos y ambas tienen casos. Los elementos son simples; en geometría figuras: triangulo, círculo, etc.; en jurisprudencia una acción: una promesa, una venta, etc. Los casos son aplicaciones de aquellas, las cuales son infinitamente variables en cada campo. Euclides compuso los Elementos de geometría; los elementos del derecho están contenidos en el Corpus iuris; pero en ambos trabajos se han agregado los casos más difíciles. Los términos simples en el derecho, sin embargo, a partir de cuya combinación surge el resto, por así decirlo, constituyen los lugares comunes y más generales, han sido recogidos por Berhard Levintheta, un monje franciscano, en su comentario sobre el Ars magna de R. Lullius. Para nosotros parece que los términos de los cuales surge la complejidad de la diversidad de los casos del derecho son personas, cosas, actos, y derechos" 26 .

De esta forma, en el derecho la combinación de los elementos (personas, cosas, actos y derechos), en sus formas simples, interpretados a la luz de ciertos principios de justicia ${ }^{27}$ puede, en teoría, dar respuesta a cualquier caso, por complejo que este parezca.

Estas ideas Leibniz las repite y reformula en diferentes momentos de su vida. Así, por ejemplo, en su Nova methodus discendae docendaeque iurisprudentiae (Nuevo método de aprender y enseñar la jurisprudencia) indica que para avanzar en una "lógica del descubrimiento" 28 , en el ámbito propio de las ciencias del derecho,

${ }^{25}$ Leibniz, G. W., De arte combinatoria, en G. W. Leibniz, Philosophical Papers and Letters (2a edición, Kluwer Academic Publishers, Dordrecht, 1989), p. 74.

${ }^{26}$ Ibíd., p. 82.

${ }^{27}$ En el De arte combinatoria (cit. n. 25, p. 74) Leibniz señala que el principio de justicia que ha de ingresar al cálculo reza de la siguiente manera: "dar a otro (o a uno mismo) todo cuanto no dañe a una tercera persona (o a otro)".

${ }^{28}$ Leibniz no usa, por cierto, esta expresión, pero nos parece que es congenial con su proyecto de uso de la lógica deductiva como motor de nuevo conocimiento y no meramente como una propedéutica del lenguaje. La idea parece haberla tomado de Peter Ramus quien desarrolló en el siglo XVI un ataque a la lógica aristotélica por considerarla desconectada de lo real. Frente a ella, 
es preciso comenzar trabajando con ciertos tópicos, es decir, "ciertas relaciones trascendentes, tales como todo, causa, materia, similitud, etc. Tal como hemos mostrado en nuestra disertación del arte de las combinaciones, las proposiciones están hechas a partir de tales relaciones de acuerdo al arte de la combinación"29. A partir de ellos, se puede proceder a un análisis, es decir, a realizar juicios. Éstos, según Leibniz, "se reducen casi completamente a la aplicación de dos reglas: i) ningún término ha de ser aceptado sin ser explicado; y ii) ninguna proposición ha de ser aceptada sin ser probada" ${ }^{30}$. Y, estas reglas, finalmente, de forma deductiva, producen sucesivas combinaciones que dan como resultado verdades necesarias ${ }^{31}$.

El corolario de todas estas ideas es que el derecho puede ser conocido mediante una adecuada aplicación del método lógico-matemático, pues "la doctrina del derecho pertenece a aquellas ciencias que dependen de definiciones y no de la experiencia; de las demostraciones racionales y no del sentido; tratan de problemas de derecho y no de hechos, por decirlo de algún modo. Puesto que la justicia consiste en una clase de congruencia y proporcionalidad, nosotros podemos entender que algo es justo incluso si no hay nadie que la practique o nadie sobre quien se practique. Así como las relaciones de los números son verdaderas aunque ninguno cuente ni haya nada que sea contado, y que podemos predecir que una casa será hermosa, una máquina eficiente, o una comunidad feliz, cuando comience a ser, aunque esto nunca suceda. No nos debe sorprender, por tanto, que los principios de esas ciencias posean verdades eternas"32.

De alguna manera muchas de estas ideas ya estaban presentes en el joven Leibniz, y por ello no nos debe extrañar que su De casibus avance en una dirección de reforma metodológica de la manera en cómo ha de entenderse el derecho, estudiarse y aplicarse. "Sus escritos estaban todo marcados con la inequívoca esperanza del joven -la convicción de que los problemas de una disciplina pueden ser resueltos recurriendo a las ideas de otros dominios, y una creencia en la aptitud de la razón, discurriendo a través de una metodología formal, para enfrentar la tarea de cualquier investigación" ${ }^{33}$.

Ramus propuso una lógica del descubrimiento a partir de ciertas categorías. Véase LEIBNIZ, G. W., Letter to Gabriel Wagner on the Value of Logic, en Philosophical Papers, cit. (n. 25), p. 464. Para una explicación simple de la significación técnica de la expresión "lógica del descubrimiento”, véase POPPER, Karl, Búsqueda sin término (Madrid, Alianza Editorial, 2002), pp. 126-139.

${ }^{29}$ Leibniz, G. W., New Method, cit. (n. 25), p. 88.

${ }^{30}$ Ibíd., p. 88.

${ }^{31}$ De esta forma, para Leibniz, "el problema fundamental de la lógica del descubrimientos es, dado un concepto como sujeto o predicado, encontrar todas las proposiciones en las cuales este se usa. Ahora, una proposición es una combinación de dos términos, un sujeto y un predicado. Así el problema se reduce al problema de la combinación”. Jourdain, Philip, The Logical Work of Leibniz, cit. (n. 24), p. 507.

${ }^{32}$ Leibniz, G. W., Elements of Natural Law, en G. W. Leibniz, Philosophical Papers, cit. (n. 25), p. 133.

${ }^{33}$ Huntington, Cairns, Leibniz's Theory of Law, en Harvard Law Review, 60 (diciembre de 1946) 2, p. 206. En este interesante trabajo de Huntington, además, es posible advertir los resortes teóricos generales del pensamiento de Leibniz en su ideario racionalista. De acuerdo a Leibniz toda la realidad ha de comparecer ante el tribunal de la razón y a éste ha de someterse. En su sistema, la naturaleza, la sociedad e incluso Dios mismo se hallan sujetos a las leyes de 


\section{Hacia una noción rigurosa del concepto.}

Pues bien, como hemos señalado unas líneas más arriba, el De casibus perplexis busca la determinación conceptual de la noción de "caso perplejo" (en este contexto también llamado "caso difícil” o "caso dudoso") en el derecho, específicamente en la etapa de interpretación y aplicación del mismo; y de los criterios racionales para la resolución de los dichos casos de una forma necesaria, predecible y universalizable. Para lograr su propósito Leibniz aplica al estudio de los casos complejos un análisis lógico matemático que, como veremos, lo conduce de manera predecible a la formulación de una solución única.

El pequeño opúsculo de Leibniz se inicia con una depuración conceptual del término "casus perplexus". Se trata de una expresión compuesta de dos elementos: la idea de "caso" y la idea de "perplejidad". Todo caso es para Leibniz en este contexto un hecho. Originalmente el término fue empleado por la ciencia física y por los geómetras para referirse a la concreción de una forma, y de ahí pasó a la moral y al derecho. En este último, específicamente, para designar al hecho ordenado por el derecho ${ }^{34}$, o lo que es igual, al supuesto de facto que opera como elemento de activación de las consecuencias normativas previstas en el derecho. La idea de perplejidad, a su vez, Leibniz la circunscribe a la noción de "nudo", en cuanto todo nudo está plegado sobre sí y, a la vez, posee la suficiente fuerza y elasticidad para mantener elementos dispares unidos entre sí. De modo tal que un caso complejo para Leibniz, resumiendo mucho las cosas, es un hecho que aparece frente al derecho como una especie de nudo, pero un nudo ciego. De esta condición (la de caso perplejo) se sigue la imposibilidad para el derecho de atribuir de manera simple las consecuencias jurídicas que de ordinario se aplicarían al hecho (de no generar una perplejidad).

Con estas primeras aclaraciones, Leibniz quiere circunscribir su análisis a un problema de interpretación y aplicación del derecho frente a un hecho. No se trata, en consecuencia, de una discusión sobre las antinomias que eventualmente pueden afectar a cualquier sistema u orden jurídico ${ }^{35}$.

la razón que, en un sentido profundo, son capaces de captar las verdades eternas y absolutas, necesarias e inmutables, en el difuso horizonte del devenir de los hechos y pensamientos en el tiempo. En tal sentido, en el campo de lo jurídico, "una de las primeras tareas de Leibniz fue situar al derecho natural sobre base racionales, y divorciarlo tanto de la teología como del absolutismo político". Y en lo que a la teología toca, Leibniz afirma que si en el dominio matemático es imposible que Dios voluntariamente puede hacer que un triángulo tenga cuatro ángulos, en el dominio propio de la moral y la jurisprudencia esto es aún más evidente. "Esto está completamente más allá de su poder mudar lo bueno en malo, lo correcto e incorrecto y viceversa. Las verdades eternas, insiste Leibniz, están por encima de la voluntad de Dios; aunque ellas no estén por sobre su entendimiento, de otra manera Dios no podría ser el más perfecto. La razón de dichas verdades eternas no se funda en la comprensión de Dios. Ellas no son verdades porque Dios las comprenda, sino más bien él debe entenderlas, gracias a su más perfecto conocimiento, porque ellas son verdades": Ibíd., p. 214.

${ }^{34}$ Leibniz, G. W., Disputatio inaguralis de casibus perplexis in jure, en Leibniz, LogicoPhilosophical Puzzles in the Law (Artosi, A. - Pieri, B. - Sartor, G. editores, New York, Springer, 2013), p. 133. Para efectos del presente artículo, tendremos a la vista el texto original de Leibniz y la traducción del mismo al inglés contenida en este libro.

${ }^{35}$ Las antinomias son contradicciones entre normas que para efectos del De casibus no entran 
Los casos perplejos, nos dice Leibniz, son aquellos que tienen la aptitud de generar una "duda" real en el operador jurídico; aunque la noción de duda tenga lógicamente hablando mayor extensión que la de "perplejidad”. La perplejidad es así una especie de duda, pero una duda que consiste en la disyuntiva de tener que aplicar una regla de derecho positivo ${ }^{36}$ a favor o en contra de una posición de facto que tiene el mismo peso relativo que su contraria y de cuya aplicación (de la regla de derecho) se sigue la desactivación de otra regla de derecho que no es su contradictoria, y que en otras circunstancias admitiría una aplicación conjunta. Lógicamente hablando, la idea de "perplejidad" se puede hacer equivalente, en este contexto, a las ideas de aporía, dilema o paradoja ${ }^{37}$, dependiendo del tipo de perplejidad que produzca.

\section{Diversos tipos de perplejidad y actitud que se puede asumir frente a ellos.}

En el De casibus los casos perplejos pueden tener por causa ya un acto de voluntad individual o colectiva (actos jurídicos unilaterales, contratos y convenciones en general), ya unas pretensiones irreconciliables respecto a un bien o posición en

en el análisis, pues en ellas no hay un problema propiamente de subsunción de un "hecho" a una norma de derecho, sino más bien dos normas que por su estructura lógica se desintegran mutuamente.

${ }^{36}$ Dicen Artosi, A. - Pieri, B. - Sartor, G., Logico-Philosophical Puzzles in the Law, cit. (n. 34), p. 75. "De acuerdo a Leibniz las perplejidades reales no pueden pertenecer al derecho natural, pues éste es el trabajo de Dios, sino sólo al derecho positivo. Tales perplejidades derivan del hecho de que la ley puede no ofrecer herramientas para resolver una contradicción en casos particulares". Sin embargo es preciso advertir inmediatamente que, desde el enfoque de Leibniz, incluso Dios mismo se encuentra ligado a la "racionalidad" del derecho natural (con lo que la afirmación precedente se inscribe en un registro iusracionalista absoluto. "Está completamente más allá de su poder (el de Dios) trocar lo bueno en malo, lo incorrecto en correcto, y viceversa. Las verdades eternas, insiste Leibniz, están por sobre la voluntad de Dios, aunque no sobre su entendimiento; de otra forma él no sería el más perfecto". Véase HunTington, Cairns, cit. (n. 33), p. 214. Ahora bien, esta racionalidad, a los ojos de Leibniz, había sido bien captada por el derecho romano clásico y, más específicamente, en la formulación de sus principios generales. "Tomando como base el derecho romano, propone rehacer las colecciones de decisiones jurídicas y reducir a principios todo el derecho vigente en el imperio -tanto el derecho privado como el público-, de forma que la legislación, la jurisprudencia y la doctrina queden expuestas en cuadros metódicos simples y fáciles de ser estudiados y aplicados de forma casi automática. Y, lo que es más importante todavía, mediante ese trabajo de reducción y corrección podía descubrirse en el mismo derecho romano justinianeo los principios de un Derecho verdaderamente racional y universal, que en el fondo no es sino el derecho natural, pues el derecho romano expresa el derecho natural": MARTíneZ TAPIA, Ramón, Leibniz y la ciencia jurídica, en Anales de Derecho, 4 (Universidad de Murcia, 1996), p. 166.

${ }^{37}$ No se trata, por cierto, de conceptos equivalentes. Lógicamente estos conceptos tienen un diferente contenido y los lógicos han sido cuidadosos en su tratamiento. Con todo, la breve síntesis que ofrece A. Guzmán a este respecto puede ser muy útil para clarificar el punto. "Llamaremos aporía al razonamiento circular, que en su conclusión torna a las premisas o las contradice, sin que sea posible salir de esta circularidad. Por paradoja entenderemos a la conclusión de un razonamiento que contradice a la opinión ordinariamente recibida y aceptada, al sentido común, a la evidencia inmediata, pero que dentro de las premisas del sistema en que fue formulada es verdadera (a menos que sea un sofisma)". GuZMÁn Brito, Alejandro, Aporías, paradojas, antinomias y dilemas en el derecho, en Revista de Ciencias Sociales, 45 (2000), p. 501. 
relación a una regla de derecho. En este último caso, la cuestión es determinar jurídicamente el orden de prelación entre las partes. A los primeros Leibniz los llama casos perplejos por disposición y a los segundos casos complejos por concurso ${ }^{38}$.

Leibniz, principalmente recurriendo al derecho romano, a modo ejemplar ofrece una serie de casos que producirían un grado de perplejidad objetiva en los operadores jurídicos (especialmente los jueces). De entre ellos, expondremos sólo tres en los que la perplejidad (más allá de tratarse de una disposición o concurso) sería de diversa naturaleza.

Dentro de los casos complejos por disposición, Leibniz en el parágrafo XIII del De casibus comenta un pasaje del jurista Africano referido a la aplicación de la lex Falcidia. Conforme a esta ley, el testador no podía disponer a título de legado de más de dos tercios de su herencia (con la finalidad de preservar como mínimo un cuarto al conjunto de los herederos testamentarios). De haber un exceso en el legado, debía éste ser reducido a los dos tercios referidos.

Pues bien, a Africano se le pregunta por el siguiente caso: uno que teniendo en su acervo hereditario 400 y que ya había dispuesto a título de legado de 300, lega a un tercero, con la condición de que no se aplique la lex Falcidia, un fundo cuyo valor es de 100 . Si no se hace efectivo el legado del fundo, no se aplica la lex Falcidia y el legado debe realizarse; pero si se realiza el legado, se cumple la condición señalada en la lex Falcidia y el legado debe ser dejado sin efecto. Como se puede advertir, este es un típico caso de aporía; pues la condición del legado del fundo está llamada a cumplirse y no cumplirse simultáneamente; o lo que es igual, cuando la condición se cumple se activa la ley y el legado cae; y si se activa la ley y el legado no se realiza, nada obsta al cumplimiento de la condición y por tanto el legado del fundo se hace exigible.

En otro caso, Leibniz en el parágrafo XVII refiere la historia de Arescua, una esclava que por disposición testamentaria sería libre una vez que diera a luz a su tercer hijo. Consecuentemente, el tercer hijo sería, a la vez, libre pues habría nacido de una madre libre. Sin embargo, sucedió que Arescua y su tercer hijo no pudieron inmediatamente obtener su libertad. Luego, en relación a la disposición en cuestión, se presentaba la paradoja que una que siendo madre de más de tres aún se mantenía esclava. La razón era que Arescua luego de su primer hijo tuvo trillizos y no habiendo claridad sobre cuál de los tres era en los hechos el tercero, dos frente a uno de ellos, y los tres frente a su madre, entorpecían la realización de la cláusula testamentaria.

Finalmente, Leibniz en el parágrafo XVI de su opúsculo refiere el caso de Protágoras y su discípulo Evatlo, un clásico y bien estudiado dilema jurídico. Resultó que Evatlo, quien no tenía el dinero para pagar las enseñanzas de Protágoras, convino con éste que recibiría la instrucción (destrezas del foro en este caso) sin necesidad de pagarla inmediatamente; pero bajo la condición de que pagaría los honorarios debidos a su maestro una vez que él (Evatlo) ganara su primer juicio. Sin embargo, aconteció que Evatlo, una vez formado en las artes de la heurística,

${ }^{38,}$ LeIBNIZ, G. W., De casibus perplexis, cit. (n. 34), p. 137: "Sed distinctiones rem expediemus: in casu perplejo vel est dispositio, vel concursus". 
retórica y dialéctica, no inició acción alguna ante el foro, cuestión que en la práctica significaba que Protágoras no podía cobrar sus honorarios.

Cansado de esperar, el maestro accionó contra el discípulo confiado en ganar. Pues, si Evatlo le vence en el foro, habrá ganado su primer juicio y, por la ley del contrato, deberá pagar; y si Evatlo pierde, por la ley del foro, igual habrá de pagar. Luego, venza o pierda Protágoras, sus honorarios están garantizados. Al parecer, con todo, como Evatlo había aprendido las lecciones de buena manera, pronto replicó a su maestro que, dada las premisas, nunca habría de pagar. Pues, si perdiere el juicio, aún no habría ganado litigio alguno y la condición, conforme a la ley del contrato, no se hubiere cumplido; pero si ganare el juicio contra Protágoras, conforme con le ley de los jueces, no debiere pagar. Luego, ganare o perdiere en el foro, no deberá pagar. Como se ve, aquí hay un dilema ${ }^{39}$.

Leibniz, por cierto, ofrece una cantidad bastante mayor de ejemplos para ilustrar las formas que puede asumir la perplejidad de un caso (en total se trata de 25 casos); sin embargo, los tres casos precedentes bastan para aclarar los problemas a los que el De casisbus pretende hacer frente.

Ante los casos perplejos caben diferentes alternativas de solución. A partir del parágrafo VI del De casibus, Leibniz comienza a delinear las diferentes estrategias de solución que, en su tiempo, había ofrecido la doctrina a propósito de estos casos. En términos muy esquemáticos el cuadro que presenta Leibniz es el siguiente:

Para algunos los casos perplejos no tienen solución y, por lo mismo el juez debe abstenerse de su conocimiento y solución. Esta primera idea es rechazada por Leibniz por la sencilla razón de que, como veremos más adelante, los casos complejos dejan de serlo cuando a ellos se aplica la recta razón bajo el método adecuado y conforme a los principios necesarios del caso.

Otros afirman que los casos complejos sí admiten solución; aunque varían significativamente en el criterio que proponen para tal fin. De modo tal que, unos sostienen que la solución se encuentra en ciertas estrategias de facto: por efecto del azar (lanzando una moneda al aire, por ejemplo); y otros proponen el criterio del juez. El juez, a su vez, para algunos puede resolver mirando a la ley (discrecionalidad reglada) y para otros de espaldas a ésta (discrecionalidad libre). Y, en uno u otro caso, podrá o no apelar a elementos religiosos, morales y políticos. Leibniz, rechaza también esta alternativa, pues los problemas jurídicos, según él, han de resolverse conforme a criterios jurídicos.

Finalmente, hay quienes afirman (entre ellos el propio Leibniz) que los casos

\footnotetext{
${ }^{39}$ Para un tratamiento acucioso y pormenorizado de los casos de la lex Falcidia y de Protágoras y Evatlo, véase GuZmán Brito, Alejandro, Aporías, cit. (n. 36). Otro ejemplo, incluso más claro de paradoja jurídica es el siguiente. Supóngase que una condición testamentaria para hacer efectivo un legado consista en que un individuo haya celebrado su décimo octavo cumpleaños y, así alcanzado la mayoría de edad. Ante el juez, sin embargo, comparece uno que habiendo tenido sólo cuatro cumpleaños es, en efecto, mayor de edad. ¿Es acaso esto posible? Lógicamente hablando resulta paradójico. La causa de esta perplejidad de debe a que hablamos de un individuo que está de cumpleaños un día 29 de febrero; es decir, de uno que nació en año bisiesto. Véase, a este respecto, BreWer, S., Law, Logic, and Leibniz. A contemporary Perspective, en Logico-Philosophical Puzzles in the Law, cit. (n. 34), p. 214.
} 
complejos hay que resolverlos desde el propio derecho, es decir, ellos requieren una solución de iure.

Esta primera determinación conceptual de las estrategias que es posible adoptar frente a un caso complejo, de inmediato pone de manifiesto la diferencia de la propuesta de Leibniz en relación al debate Hart-Dworkin. En efecto, aunque los tres están de acuerdo en que los casos complejos han de ser resueltos, en el esquema de Leibniz las posiciones de Hart y Dworkin se encuentran dentro de las estrategias de facto que miran a la actividad del juez. En el caso de Hart se trata de un juez cuya discreción se encuentra en parte reglada y en parte liberada por el propio derecho positivo y la naturaleza de sus reglas (textura abierta de la norma); en el caso de Dworkin se trata de un juez que ha de buscar la solución en el extrarradio jurídico, teniendo en consideración su "background culture" específico (moral y político).

\section{Las estrategias de solución propuestas por Leibniz.}

Leibniz insiste en la idea de que los casos perplejos han de ser resueltos desde el derecho y por el derecho. Llegado a este punto formula su teoría de la única solución correcta para este tipo de casos. Por la importancia del texto lo citaremos de manera íntegra: "En cuanto nosotros, esperamos que todos los casos puedan ser decididos sobre fundamentos de mero derecho, como ha sido establecido en la Glosa del Landrecht I,33, nota 2 ("wenn es ist kein Sache, do thu das Rect. Zu, als die Ertzen zu der Geuche", i.e., "no hay caso respecto del cual el derecho no se pueda aplicar, tal como no hay enfermedad que rechace absolutamente cualquier medicina") y por Treuler en la mencionada ley./ Bachov no está de acuerdo, argumentando que la interpretación de las leyes positivas es bastante incierta, y frecuentemente hay demasiada incertidumbre en saber qué opinión es la más aceptada en la práctica, porque hay una enorme cantidad de opiniones comúnmente compartidas./ Sin embargo, las leyes positivas descansan en la razón civil, la cual limita la ley de la naturaleza y las naciones a modo de excepción, y más particularmente una restricción. Por tanto, la ley de la naturaleza y las naciones se mantendrá en un caso dado tanto como no se pruebe que lo contrario ha sido introducido mediante un estatuto, como un acuerdo general del pueblo (incluso la aptitud del Príncipe de hacer leyes deriva del consentimiento que el pueblo le ha dado a él). Y en efecto, si la interpretación es incierta, nosotros debemos recurrir a las reglas de interpretación de la razón natural, e incluso si tales reglas y presunciones dan igual fuerza a las posiciones de ambas partes, debemos fallar en contra de la parte que funda su demanda en una ley de derecho positivo pero que no puede establecer suficientemente que esa ley ha sido promulgada./ Así se hace claro que todo puede en efecto siempre ser decidido sobre las bases del mero derecho natural y las naciones, bajo el cual nada es incierto, como el mismo Bachov reconoce. Teniendo así por establecido que tales casos pueden decidirse de acuerdo al derecho, todas las opiniones previas fallan, pues lo primario, en virtud de su existencia, prima sobre lo secundario, de acuerdo a I.1\&3 De dolo et malo" ${ }^{40}$.

${ }^{40}$ Leibniz, G. W., De casibus, cit. (n. 34), pp. 82-83. 
Puede parecer extraño que Leibniz afirme que los casos perplejos se resuelven sólo desde el derecho (de iure) y luego, en el mismo párrafo, introduzca nociones, en principio, ajenas al derecho (razón natural, por ejemplo). Sin embargo, dentro de su pensamiento no hay contradicción alguna, pues la idea de "derecho" en este contexto no se limita al ámbito del derecho positivo. Este último (el derecho positivo) es ya una determinación, ya una restricción (razonada excepción) de los principios de la razón natural y el derecho de gentes. Y estos últimos, por cierto, no son nada más que aquellos principios de interpretación racional (lógicomatemáticos) de la ley positiva o, mejor aún, principios contenidos en el derecho común alemán de la época (básicamente derecho romano) que son congeniales con dicha racionalidad natural. En esta dirección, ya lo hemos señalado, el derecho es para Leibniz un principio formal de acción racional eterno, inmutable e independiente incluso de Dios mismo ${ }^{41}$.

Así, la determinación de los principios jurídicos parece avanzar en dos etapas. Primero ha de haber una suerte de depuración lógica de los enunciados (con contenido de facto) que son sometidos al arbitrio del juez (o del jurista). En este caso el análisis lógico busca aclarar la naturaleza y secuencias de las razones que se introducen en una discusión jurídica. En segundo lugar, ha de aplicarse el método deductivo a la formulación de categorías jurídicas o principios explicativos o regulativos en el derecho.

Como ha advertido Brewer ${ }^{42}$, siguiendo en esto a Quine, la depuración lógica de los enunciados con contenido jurídico en una discusión sobre un caso difícil puede ser de gran utilidad si la dificultad consiste precisamente en un error en el razonamiento. De modo tal que es posible afirmar que ciertos casos complejos se pueden resolver mediante estrategias lógicas. Así, en las llamadas "paradojas verídicas", en que la perplejidad consiste en lo anómalo de una opinión aunque esta puede ser perfectamente verdadera, la solución pasa por la demostración o prueba de la opinión en controversia. El caso de la esclava Arescua puede ilustrar el punto, en cuanto a que, por difícil que parezca a primera vista, una que sólo ha dado a luz dos veces pueda haber concebido a cuatro hijos. Aquí la dificultad se resuelve en cuanto se prueba que Arescua ha dado a luz, en su segundo parto, a trillizos. El propio Leibniz avanza en esta estrategia en su opúsculo, concluyendo que una vez resuelto el entuerto e incluso no pudiendo probarse cuál de los trillizos es el tercero y libre, conforme al principio de la libertad (que también tienen una base jurídica $\left.{ }^{43}\right)$, los tres y Arescua han de ser liberados.

Otro tanto sucede en las "falsas paradojas" que se producen por la presencia de argumentos falaces de diversa índole dentro de un razonamiento. Así, cuando un caso difícil es tal porque, por ejemplo, se han introducido en el razonamiento paralogismos (un paralogismo del cuarto término, por ejemplo), falacias de composición o división (que en el opúsculo de Leibniz se pueden asociar a los

\footnotetext{
${ }^{41}$ Véase Leibniz, G. W., Meditación sobre la noción común de justicia, en G. W. Leibniz, Escritos de filosofía jurídica y politica (Madrid, Biblioteca Nueva, 2001), pp. 81-87.

${ }^{42}$ BREWER, Law, Logic, and Leibniz, cit. (n. 38), pp. 212-224.

${ }^{43}$ Leibniz, G.W., De casibus, cit. (n. 34), p. 89, donde cita la norma contenida en la 1.16 Cod. De fideicommissariis libertatibus (= Cod. Iust. 7,4,16).
} 
problemas de "transitividad"), etc., también el caso puede y debe ser resuelto a la luz de un esclarecimiento lógico. El caso de Protágoras y su discípulo Evatlo sirve para ilustrar esta estrategia.

Como se recordará, Evatlo había convenido en pagar los honorarios de Protágoras una vez que ganara su primer juicio que, como sabemos nunca inició. Lógicamente hablando se trata de un enunciado condicional del modo: "Si ganas tu primer juicio, entonces pagas mis honorarios”. Luego, de la realización de la condición se sigue la activación de lo condicionado; pero de la falsedad del condicionado lo único que se infiere lógicamente es la no realización del condicionante. Esto explica por qué razón Leibniz lógicamente insiste en que este caso se resuelve, primero a favor de Evatlo (mediante la figura de una excepción dilatoria), pues al momento de accionar Protágoras la condición no se había cumplido; pero luego, una vez vencido, a Protágoras le asiste el derecho en contra de Evatlo de exigirle el pago de sus honorarios ${ }^{44}$.

Finalmente, encontramos las "paradojas antinómicas" respecto de las cuales los rudimentos meramente lógicos no son suficientes, aunque siguen siendo necesarios. Son estas las paradojas que representan un verdadero desafío para el joven Leibniz y respecto de las cuales el De casibus pretende ser un aporte novedoso.

Leibniz nos ofrece varios ejemplos de estas paradojas a propósito de los concursos en los cuales los órdenes de prelación entre sujetos en competencia se pueden ver alterados por diferentes disposiciones incompatibles. Sin embargo, volveremos sobre el ejemplo de la aplicación de la lex Falcidia, por sernos ya conocido.

El problema que comenta Leibniz a propósito de la lex Falcidia, se recordará, tiene que ver con la aporía que se produce respecto al supuesto de aplicación de la ley y el legado condicional de un fundo por un valor de 100. De forma tal, que si se respeta el legado, se aplica la ley; y si no se realiza el legado, no se aplica la ley y el legado debe realizarse. Pues bien, respecto a estos casos, en los que dos disposiciones jurídicas se anulan mutuamente frente a un supuesto de hecho, no siendo posible desactivar una sin activar la otra y viceversa, las reglas de la lógica no son suficiente guía para la resolución del asunto (aunque no ha de prescindirse de ellas). Sin embargo, esto no quiere decir, en modo alguno, que no exista una solución de derecho para estos casos. El propio Leibniz, específicamente comentando este caso, nos indica mediante las referencias bibliográficas, cuál es la solución de iure.

En efecto, el pasaje que comenta Leibniz pertenece al libro V de las Quaestiones del jurista Africano y se conserva en Digesto 35,2,88 pr. En él, y una vez formulada la aporía, Africano expone su solución al caso: apelando a la voluntad del testador, la que en la especie parece orientarse por la idea de que no se perjudique a los otros legados con la eventual entrega del fundo (legado que vale por

${ }^{44}$ Véase Leibniz, G. W., De casibus, cit. (n. 34), p. 88. En la misma dirección avanza Leibniz (ibíd., pp. 95-98) en los casos de los parágrafos XXII a XXIII, en los cuales, a propósito de la historia propuesta por Schwenter y de los casos de la dote matrimonial y la hipoteca, muestra como en muchos casos de perplejidad ella se deriva simplemente de falacias a secundum quid ad simpliciter. 
100), la solución de derecho propuesta consiste en no tener por no cumplida la condición del legado del fundo.

Comentando con detalle este pasaje, Guzmán ha reconducido la solución de Africano a la aplicación de un principio general de interpretación de los testamentos en el derecho romano, según el cual "estos deben entenderse a la luz de la sententia o mens testatoris, vale decir, de aquello efectivamente querido o pensado por el testador" 45 . Así las cosas, "la conclusión que obtenemos del examen de este caso es que bien puede ser que un caso sea aporético desde el punto de vista lógico y otra que lo sea desde el punto de vista jurídico. Aquél nos demuestra que un caso lógicamente aporético puede encontrar perfecta solución merced a la aplicación de los cánones jurídicos" ${ }^{46}$.

El tránsito que propone Leibniz desde una solución conforme a los principios de la lógica hacia una solución jurídica de acuerdo a los principios del derecho es perfectamente coherente dentro de su teoría de la única solución adecuada. Leibniz, una y otra vez vuelve sobre casos concretos extraídos del derecho romano (derecho común de su época) y del derecho nacional y muestra cómo los juristas construyen sus soluciones a partir de unos procesos deductivos bien definidos, aunque no siempre totalmente comprendidos. El caso paradigmático lo presenta el derecho romano y la actividad de sus juristas y, por lo mismo, Leibniz prefiere exponer su teoría dentro de la tradición romanista, pero aclarada desde una perspectiva racional. Esto explica por qué "en muchas de sus cartas y trabajos académicos Leibniz comparó el trabajo de los juristas romanos clásicos al de los antiguos matemáticos y geómetras. En una carta a Georg Graevius él comentó: creo que ni Euclides ni Descartes, si ellos mismos se hubiesen dedicado a esta doctrina, habrían sido capaces de escribir con más profundad o extensión que Ulpiano y Papiniano" ${ }^{47}$.

En otros términos, lo que Leibniz advierte con fuerza en el derecho romano clásico (aunque no sólo en él) es la protoforma de un derecho racional de cuño lógico deductivo capaz de extraer principios de justicia universales a la luz de los cuales puede resolverse cualquier tipo de perplejidad en el derecho. No se trata, claro está, de principios meramente lógicos, sino de verdaderos principios jurídicos que, sin estar reñidos con la lógica, van más allá de ésta y representan la última ratio de solución.

Leibniz, con todo, advierte que el trabajo de los juristas clásicos tuvo un fuerte componente intuitivo, pues dichos juristas no tuvieron del todo conciencia del método adecuado para el análisis de su objeto. Y este es, en gran medida, el problema que el De casibus pretende solucionar. De ahí que de manera natural, Leibniz nos ofrezca la solución de los casos complejos (especialmente las aporías por disposición o concurso) mediante la formulación de principios y, al final del escrito, nos indique con claridad el propósito último de la implementación de un

\footnotetext{
${ }^{45}$ GuZmán Brito, Alejandro, Aporías, cit. (n. 36), p. 514.

${ }^{46}$ Ibíd., p. 515.

${ }^{47}$ Hoeflich, M. H., Law and Geometry: Legal Science from Leibniz to Langdell, en The American Journal of Legal History, 30 (abril de 1986) 2, p. 100.
} 
método racional lógico deductivo para el análisis de lo jurídico y de la formulación de principios propiamente jurídicos.

Los principios que Leibniz propone en este trabajo temprano son tres. Uno referido a las perplejidades que suponen las disposiciones y dos para las perplejidades por concurso. Respecto a la dispositio Leibniz señala que el principio es "toda disposición que produzca perplejidad ha de ser inválida, y quien pretenda fundar su pretensión en ella no ha de obtener nada" ${ }^{48}$. En cuanto al concursus, Leibniz agrega otros dos principios: primer principio: cuando el contenido de una pretensión concursal no pueda ser dividido y no se admita un dominio común respecto a la misma, todas las partes en competencia se entenderá que pierden ${ }^{49}$. Por el contrario, segundo principio: cuando la cosa objeto de la pretensión concursal pueda ser dividida o susceptible de dominio compartido, todas las partes en competencia han de tener algún derecho a prorrata ${ }^{50}$.

Con razón, alguno ${ }^{51}$ ha criticado el opúsculo de Leibniz por su poca sustantividad. Los principios propuestos en el De casibus para la solución de los casos complejos no son nuevos, dado que de una u otra forma ya estaban presentes en la tradición romanista. Además, en su número y posibilidad, el propio Leibniz lo advierte, dichos principios son por cierto insuficientes para dar cuenta de todos los casos complejos. Sin embargo, no debemos buscar en estos tres principios, propuestos a modo ejemplar, el valor del De casibus, sino en el sentido y alcance que tiene la estrategia de Leibniz. En efecto, el De casibus concluye con una lista de seis corolarios y dentro de ellos, es el número tres el que da cuenta del proyecto general del opúsculo.

"El vicio primario de un escritor -dice Leibniz en el corolario número treses dividir en innumerables fragmentos aquellas cuestiones que caen dentro de la extensión de una única comprensión (Cujas, IX, observación 38), i.e., introducir bajo subcategorías separadas lo que puede ser comprendido de un vistazo desde una regla general, sólo para hacer los libros más largos. De ahí que los pesados

${ }^{48}$ Así, por ejemplo, la disposición testamentaria que liberaba a Arescua y a su tercer hijo, cuyo sujeto obligado era el sucesor (uno o varios) del causante, ante la perplejidad (no especificación de la condición de "tercer hijo"), queda sin efecto para el titular de la sucesión que pretenda, fundándose en ella, mantener en la condición de esclavitud a Arescua y a sus trillizos.

${ }^{49}$ Desde el párrafo XXIV a XXVI Leibniz entrega ejemplos de esta situación. En palabras simples, el caso propuesto en el párrafo XXVI nos puede servir para esclarecer la aplicación de este principio. Trátase ahí de determinar el orden de prelación para la titularidad de un privilegio (indivisible). El problema se produce cuando dado el orden de prelación A antecede a B y B a C; conforme al derecho común, una disposición especial altera la preferencia de C respecto de $\mathrm{A}$; pero no la de $\mathrm{A}$ respecto de $\mathrm{B}$, ni la de $\mathrm{B}$ respecto de $\mathrm{C}$. De modo tal que ahora tenemos que $\mathrm{C}$ precede a $\mathrm{A}$; pero $\mathrm{A}$ precede a $\mathrm{B}$, pero $\mathrm{B}$ precede a $\mathrm{C}$. Luego, ¿quién de los tres es el titular del privilegio? En un caso así, y no siendo posible establecer un orden de prelación concursal de acuerdo a ninguna regla, Leibniz sostiene que el privilegio no ha de ser diferido a ninguno (A, B o C).

${ }^{50} \mathrm{Si}$ el caso de la nota 47 , por el contrario, se produjese a propósito de una masa hereditaria, Leibniz señala que, no pudiendo establecerse un orden de prelación determinado entre los herederos, todos llevarían igual cuota, o dominio sobre los bienes (regla 2).

${ }^{51}$ Véase Artosi, A. - Pieri, B. - Sartor, G., Leibniz, Logico-Philosophical Puzzles in the Law, cit. (n. 34), pp. xxix-xxxi. 
trabajos de Menochius, De praesumptionibus, y de Mascardi, De probationibus, puedan ser cada uno reducidos a seis cortas páginas, de manera tal que dichas páginas contengan toda la verdad que de tales trabajos se puede derivar" ${ }^{2}$.

En este pequeño fragmento, Leibniz, por una parte, da cuenta de uno de los propósitos del De casibus (la determinación de principios básicos del derecho) y, por otra, anticipa su proyecto teórico-jurídico futuro: la reforma metodológica y sustantiva de la forma en que el derecho se genera, aprende, interpreta y aplica. Posteriormente estas ideas las desarrollará, fundamentalmente en su Nuevo método para el aprendizaje y la enseñanza de la jurisprudencia. Así, en el ideario de Leibniz, una vez que la razón lógico deductiva haya sido consistentemente introducida en el análisis de lo jurídico necesariamente ha de descubrir ciertos principios propios del derecho que, en número finito y racionalmente aplicados, tengan la aptitud de disolver a través de una única interpretación todo caso complejo, o, lo que es igual, sirvan para demostrar que a la luz de los tales principios no existen, en estricto rigor, casos complejos.

\section{A MOdo de CONClusión: Un CONTRApunto ENTRE las ideas de "CASO difícil” en el debate Hart-Dworkin y “Caso perplejo” en Leibniz}

Como hemos tenido ocasión de ver, la discusión contemporánea de los “casos difíciles" dentro del contexto del debate Hart-Dworkin avanza en la determinación y solución del problema de las relaciones entre derecho y moral y la discrecionalidad de los jueces. Se trata de una pregunta por el sentido y contenido del derecho, incluso cuando no hay norma expresa. De hecho ese parece ser el supuesto del problema: la falta de regla que dirima el problema o la ambigüedad de la misma y la disonancia de los recursos para su interpretación. En el caso de Leibniz esa no es la cuestión. Dentro de su teoría del derecho positivo no cabe el problema de los "vacíos", toda vez que el derecho positivo es concebido como una determinación o excepción del derecho racional; de manera tal que lo que torna a un caso complejo es la capacidad que tiene éste de evidenciar una incoherencia lógica o una inconsistencia (por falta de principios adecuados) dentro de un sistema jurídico.

Por lo anterior, la controversia a propósito de los "hard cases" en el debate anglosajón gira en torno a problemas sustantivos, esto es, sobre los recursos de los que disponen los operadores jurídicos para interpretar las normas ambiguas o llenar los vacíos legales. Leibniz, por el contrario, avanza en otra dirección. Aunque el problema de los casos complejos tiene que ver con la interpretación y aplicación del derecho (incluso en sede judicial), lo fundamental de su estudio estriba en la comprensión misma de la dificultad como elemento de justificación de una reforma metodológica que supere toda aporía jurídica. En otros términos, en el caso de Leibniz, el caso complejo es un elemento metodológicamente ilustrativo de la forma en que se desarrollan, por parte del operador jurídico juez, razonamientos incorrectos, sea formalmente o materialmente. Esta razón explica, por qué el corolario cuarto del De casibus, que distingue entre teoría y práctica

${ }^{52}$ Leibniz, G. W., De casibus, cit. (n. 34), pp. 117-118. 
jurídica, concluya con una cita a Bachov en la que se advierte que aunque para la solución de los casos concretos el juez pueda siempre apelar a la autoridad del soberano político (quien expresa su voluntad a través de la ley), nadie ha de afirmar que la autoridad del soberano "puede suplantar la verdad y la razón de las cosas" 53.

La idea propuesta por Leibniz de retrotraer el análisis de los casos complejos a un estadio de análisis conceptual anterior a la consideración del caso complejo de facto (de naturaleza contingente y accidental) marca otro gran desacuerdo con el debate Hart-Dworkin. En efecto, más allá de sus diferencias, Hart y Dworkin realizan respecto a los "hard cases" un análisis a posteriori, esto es, una vez producido el caso ha de buscarse la solución. En uno y otro pensador los "hard cases" son anomalías propias y necesarias de todo sistema jurídico, aunque como sabemos difieren en las estrategias de solución. Leibniz, por su parte, nos propone un tipo de análisis a priori de los razonamientos que conducen a la errónea idea de que existen, en realidad, casos complejos, cuando lo que efectivamente ocurre es que existen malos razonamientos. En palabras sencillas, de acuerdo a Leibniz la cuestión de los casos complejos no puede residir en la exposición del caso concreto anómalo, cuestión tan absurda como pretender que un matemático una y otra vez intente explicar por qué la cifra "cinco" aparece anómalamente como producto de la sumatoria "dos más dos" (cuyo producto es cuatro), a partir de la consideración del producto anómalo (cinco) y no de la deficiente operación.

Resulta fácil de entender también, más allá de la apariencia nominal, por qué razón las ideas de Dworkin y su teoría de la solución única no son susceptibles de ser asimiladas a las ideas de Leibniz (quien también promueve, como hemos visto, una teoría de la única solución correcta). Dworkin, al igual que Leibniz, distingue con claridad la teoría y la práctica del derecho, y para efectos de elaborar su teoría de la única solución adecuada recurre a la figura imaginaria del juez Hércules (que está de parte de la teoría). Éste, como hemos visto, mediante su incomparable capacidad de trabajo e inteligencia, y teniendo todos los elementos de juicio que están de hecho presentes en su "background" social, está en condiciones de emitir un juicio de derecho respecto a "casos difíciles" que en la especie es, de hecho y de derecho, el más adecuado, al ser congenial racionalmente con los valores políticos, morales y jurídicos de su contexto. De modo tal que, "cuando un nuevo caso surja, él podría estar bien preparado. Desde fuera -comenzando, tal vez, por la extensión intergaláctica de su creación intelectual- él podría en lo concerniente al problema en cuestión, de manera constante, encontrar la mejor justificación a mano para el derecho en general, para la práctica legal y constitucional americana como una especie del derecho, para la interpretación constitucional, el juicio concreto, y luego, finalmente, para la pobre mujer que toma muchas píldoras y el hombre indignado que quema su bandera" ${ }^{24}$.

En todo caso, el juez Hércules realiza su trabajo desde fuera del sistema, y como un observador universal está en condiciones de ofrecernos una solución satisfactoria para cada caso, toda vez que su labor se desarrolla de manera re-constructiva y

\footnotetext{
${ }^{53}$ Ibíd., p. 118.

${ }^{54}$ Dworkin, Ronald, Justice in Robes (London, Harvard University Press, 2006), p. 54.
} 
coherente dado el trasfondo cultural al que pertenece. De inmediato se advierten dos características del producto esperado de la actividad del juez Hércules: $i$ ) Èste no realiza ninguna crítica al sistema de valores en el cual desarrolla su misión (es por así decirlo, un actor bastante conservador), sino que simplemente se dedica a aplicarlos a un caso particular; ii) la solución, al caso sometido a su conocimiento aunque es única dentro del sistema, es relativa frente al derecho (al derecho más allá de los Estados Unidos de América).

Leibniz nunca desconoció que la actividad jurisdiccional se realiza en un contexto social bien definido, pero como hemos visto, descarta de forma explícita la posibilidad de introducir en el razonamiento judicial razones del extrarradio jurídico (religiosas, morales y políticas); pues lo que nos propone es una solución de mero iure. Además, Leibniz tampoco promueve una solución relativa (o abierta) para los casos complejos, sino una universal y racional, válida en todo tipo de sistema jurídico.

Finalmente, Leibniz niega la posibilidad de transferir a los jueces la responsabilidad de decir conjeturalmente y de acuerdo a su especial contexto social, lo que el derecho es. De esta forma, como ha dicho Ben-Menahem, "nosotros advertimos un número de diferencias entre Leibniz y Dworkin. Dichas diferencias indican que la afirmación de una única solución dentro del derecho es insuficiente para caracterizar una teoría legal en general. Leibniz y Dworkin difieren en sus concepciones sobre el proceso legal (gobernado por reglas - de final abierto), y en sus concepciones del material legal (exclusivo-inclusivo), aunque ellos están de acuerdo en la existencia de una única solución dentro del derecho y niegan (de manera contundente) la discreción judicial. Pero aunque ellos coinciden en esto, arriban a sus conclusiones por unos caminos muy diferentes: Leibniz minimizando el ámbito de la intervención legal, Dworkin maximizándolo" 55 .

Probablemente existan más diferencias entre las ideas de Hart, Dworkin y Leibniz en esta materia; sin embargo, las que hemos señalado dan cuenta suficiente de la inconmensurabilidad de las teorías. No es, por cierto, el propósito de este artículo pronunciarnos a favor de alguna de ellas en particular, sino simplemente mostrar con relativa claridad que la discusión sobre los "casos difíciles" no se agota en el debate Hart-Dworkin y que es perfectamente posible explorar, desde la tradición racional, otras estrategias de solución. Dentro de estas últimas, no nos cabe duda alguna, la propuesta por Leibniz puede ser un buen punto de partida.

\section{BiBLIOGRAFÍA}

Artosi, A. - Pieri, B. - Sartor, G., Leibniz: Logico-Philosophical Puzzles in the Law (New York, G., Springer, 2013).

Ben-Menahem, Hanina, Leibniz on Hard Cases, en Archives for Philosophy of Law and Social Philosophy, 79 (1993).

Brewer, S., Law, Logic, and Leibniz. A contemporary Perspective, en Logico-Philosophical Puzzles in the Law (New York, Springer, 2013)

${ }^{55}$ Ben-Menahem, Hanina, Leibniz on Hard Cases, en Archives for Philosophy of Law and Social Philosophy, 79 (1993), p. 214. 
Dworkin, Ronald, The Model of Rules (1967), Faculty Scholarship Series, Paper 3609.

Dworkin, Ronald, Hard Cases en Harvard Law Review, 88 (1975).

Dworkin, Ronald, Social Rules and Legal Theory, en Yale Law Journal, 81 (1972).

Dworkin, Ronald, El Imperio de la justicia (Barcelona, Gedisa, 2005).

Dworkin, Ronald, Justice in Robes (London, Harvard University Press, 2006).

Foucault, Michele, Los anormales (Buenos Aires, Fondo de Cultura Económica, 2010).

GuZMÁn Brito, Alejandro, Aporias, paradojas, antinomias y dilemas en el Derecho, en Revista de Ciencias Sociales, 45 (2000).

Hart, H. L. A., "Post Scriptum" a su libro El concepto de derecho (México, Universidad Nacional Autónoma de México, 2000).

HarT, H. L. A., El concepto de derecho (Buenos Aires, Abeledo-Perrot, 1998).

Hoeflich, M. H., Law and Geometry: Legal Science from Leibniz to Langdell, en The American Journal of Legal History, 30 (abril de 1986) 2.

Holmes, O. W., Fallo de disenso en "Securities Co. v. United Status", 193, U.S., 197, 400-1 (1904).

Huntington, Cairns, Leibnizs Theory of Law, en Harvard Law Review, 60 (diciembre de 1946) 2.

JourdaIn, philip, The Logical Work of Leibniz, en The Monist, 26 (octubre de 1916) 4.

Leibniz G. W., New Method for Leaerning and Teaching Jurisprudence, en G. W. Leibniz, Philosophical Papers and Letters (2a edición, Kluwer Academic Publishers, Dordrecht, 1989).

Leibniz, G. W., De arte combinatoria, en G. W. Leibniz, Philosophical Papers and Letters (2a edición, Kluwer Academic Publishers, Dordrecht, 1989).

Leibniz, G. W., Elements of Natural Law, en G. W. Leibniz, en G.W. Leibniz, Philosophical Papers and Letters (2a edición, Kluwer Academic Publishers, Dordrecht, 1989).

Leibniz, G. W., Letter to Gabriel Wagner on the Value of Logic, en G. W. Leibniz, Philosophical Papers and Letters (2a edición, Kluwer Academic Publishers, Dordrecht, 1989).

Leibniz, G.W., Meditación sobre la noción común de justicia, en G. W. Leibniz, Escritos de filosofia jurídica y politica (Madrid, Editorial Biblioteca Nueva, 2001).

LeIBniz, G.W., Disputatio inaguralis De casibus perplexis in jure, en Leibniz, LogicoPhilosophical Puzzles in the Law (Artosi, A. - Pieri, B - Sartor, G., editores, New York, Springer, 2013).

Martínez Tapia, Ramón, Leibniz y la ciencia jurídica, en Anales de Derecho, 4 (Universidad de Murcia, 1996).

Popper, Karl, Búsqueda sin término (Madrid, Alianza Editorial, 2002).

Rostow, Eugene, Great Cases Make Bad Law: The War Powers Act en Texas Law Review, 50 (mayo de 1972) 5.

Shapiro, Scott J., The "Hart-Dworkin" Debate: A Short Guide for the Perplexed en Public Law and Legal Theory Working, Paper Series, Working Paper, 77 (marzo de 2007).

SHAUER, Fedrick, Do Cases Make Bad Law, en The University of Chicago Law Review, 73 (2006) 3.

White Speight, Hallie, Hard Cases make Bad Law: Commonwealth v. Adjutant and Evidence of the Deceased's Propensity for Violence in Self. Defense Cases in Massachussets, en Boston University Law Review, 86 (2006) 3. 
